\title{
Doses de potássio para o sorgo sacarino destinado à produção de etanol
}

\section{João Victor Silva BERNARDES ${ }^{1 *}$, Valdeci ORIOLI JÚNIOR ${ }^{1}$, Hamilton César de Oliveira CHARLO ${ }^{1}$, Gislaine FERNANDES ${ }^{1}$, Luiz Paulo Venesiano BOSCO ${ }^{1}$}

\author{
${ }^{1}$ Instituto Federal de Educação Ciência e Tecnologia do Triângulo Mineiro, Uberaba, Minas Gerais, Brasil \\ *E-mail: valdeci@iftm.edu.br
}

Recebido em janeiro/2018; Aceito em agosto/2018.

\begin{abstract}
RESUMO: O presente estudo objetivou avaliar os efeitos de doses de $\mathrm{K}$ em atributos morfológicos, produtivos e qualitativos do sorgo sacarino. O experimento foi conduzido em campo em Latossolo Vermelho com teor inicial de $0,6 \mathrm{mmol}_{\mathrm{c}} \mathrm{dm}^{-3} \mathrm{de} \mathrm{K}$. Adotou-se o delineamento em blocos casualizados com cinco tratamentos $(0,50,100$, 150 e $200 \mathrm{~kg} \mathrm{ha}^{-1} \mathrm{de} \mathrm{K}_{2} \mathrm{O}$ ) e quatro repetições. Avaliaram-se: diâmetro de colmos, altura de plantas, teor de $\mathrm{K}$ na folha e no caldo, produção de colmos e de caldo e concentração de açúcar total no caldo. Os dados foram submetidos à análise de variância e de regressão polinomial. $\mathrm{O}$ fornecimento de $\mathrm{K}$ incrementou linearmente $\mathrm{o}$ diâmetro do colmo e aumentou a altura de plantas até a dose de $152 \mathrm{~kg} \mathrm{ha}^{-1} \mathrm{de}_{2} \mathrm{O}$. O maior diâmetro e altura foi, respectivamente, $18,1 \mathrm{~mm}$ e 2,73 $\mathrm{m}$. A adubação potássica não afetou o teor de $\mathrm{K}$ nas folhas, mas elevou a produção de colmos até $32.454 \mathrm{~kg} \mathrm{ha}^{-1}$ com aplicação de $132 \mathrm{~kg} \mathrm{ha}^{-1}$ de $\mathrm{K}_{2} \mathrm{O}$. Houve incremento linear na produção de caldo, chegando-se a $7.322 \mathrm{~L} \mathrm{ha}^{-1}$. A dose de, aproximadamente, $100 \mathrm{~kg} \mathrm{ha}^{-1} \mathrm{de} \mathrm{K}_{2} \mathrm{O}$ proporcionou as maiores concentrações de açúcar total $\left(62,7 \mathrm{mg} \mathrm{L}^{-1}\right)$ e $\mathrm{K}$ no caldo $\left(1.144 \mathrm{mg} \mathrm{L}^{-1}\right)$.
\end{abstract}

Palavras-chave: Sorghum bicolor, biocombustível, adubação potássica.

\section{Potassium rates for sweet sorghum cultivated for ethanol production}

\begin{abstract}
The objective of this study was to evaluate the effects of $\mathrm{K}$ rates on morphological, productive and qualitative attributes of sweet sorghum cultivated for ethanol production. The experiment was conducted in field conditions in a cerrado soil with $0.6 \mathrm{mmol}_{\mathrm{c}} \mathrm{dm}^{-3}$ of $\mathrm{K}$. The randomized block design with five treatments $\left(0,50,100,150\right.$ and $200 \mathrm{~kg} \mathrm{ha}^{-1}$ of $\left.\mathrm{K}_{2} \mathrm{O}\right)$ and four replicate was adopted. The following variables were evaluated: stem diameter, plant height, leaf and juice $\mathrm{K}$ content, stem and juice yield, and total sugar concentration in the juice. Data were submitted to analysis of variance and polynomial regression. The K supply linearly increased stem diameter and increased plant height up to the $152 \mathrm{~kg} \mathrm{ha}^{-1}$ of $\mathrm{K}_{2} \mathrm{O}$ rate. The largest diameter and height were, respectively, $18.1 \mathrm{~mm}$ and $2.73 \mathrm{~m}$. Potassium fertilization did not affect the leaves $\mathrm{K}$ content, but increased stem yield up to $32,454 \mathrm{~kg} \mathrm{ha}^{-1}$ with application of $132 \mathrm{~kg} \mathrm{ha}^{-1}$ of $\mathrm{K}_{2} \mathrm{O}$. There was a linear increase in juice yield, reaching 7,322 $\mathrm{L} \mathrm{ha}^{-1}$. The rate of approximately $100 \mathrm{~kg} \mathrm{ha}^{-1}$ of $\mathrm{K}_{2} \mathrm{O}$ provided the highest total sugar $\left(62.7 \mathrm{mg} \mathrm{L}^{-}\right.$ ${ }^{1}$ ) and $\mathrm{K}$ concentrations in the juice $\left(1,144 \mathrm{mg} \mathrm{L}^{-1}\right)$.

Keywords: Sorghum bicolor, biofuel, potassium fertilization.
\end{abstract}

\section{INTRODUÇÃO}

O Brasil é um dos maiores produtores de etanol do mundo e praticamente a totalidade deste combustível é gerada tendose a cana-de-açúcar como matéria prima. Na última safra foram produzidos mais de 27 milhões de metros cúbicos de etanol no país (MAPA, 2017).

A maior parte deste volume é produzida no período de safra da região Centro-Sul do país, entre os meses de maio a novembro. Assim, durante a entressafra da cultura nesta região a produção nacional de etanol diminui substancialmente. Consequentemente, esta alternância na produção e oferta do combustível promove grande oscilação no preço do etanol durante $o$ ano.

Com o intuito de reduzir o período ocioso, as indústrias do setor sucroenergético têm avaliado a possibilidade de produção deste combustível a partir do caldo de colmos de sorgo sacarino, uma vez que este pode ser cultivado durante a entressafra da cana-de-açúcar. Ainda, a adoção dessa estratégia evita a redução drástica na oferta de etanol no mercado durante os meses de dezembro a abril, com isso o preço do biocombustível tende a se manter estável (MAY et al., 2013).

O sorgo sacarino é uma cultura cultivada no verão (entressafra da cana-de-açúcar), de ciclo curto e com altos teores de açúcares diretamente fermentáveis no colmo. Caracteriza-se, ainda, por ser tolerante a estresses abióticos, o que favorece seu desenvolvimento em condições edafoclimáticas diversas e a torna promissora fonte de matéria prima para produção de etanol no país. Ainda, vale ressaltar que tanto o processo de colheita quanto o de beneficiamento são os mesmos adotados para a cana-de-açúcar, não sendo necessárias mudanças adaptativas. O sorgo sacarino pode ser cultivado em área de reforma de canavial, não havendo necessidade de abrir novas áreas para a implantação (DURÃES, 2011; ALMODARES; HADI, 2009).

Diversos experimentos têm mostrado as potencialidades do sorgo sacarino para produção de etanol (RAUPP et al., 1980; LOURENÇO et al., 2007; ALMODARES; HADI, 2009). No entanto, embora os estudos com esta cultura tenham se iniciado por volta de 1975 no Brasil, poucas informações 
obtidas no país que subsidiem as recomendações de adubação estão disponíveis. Ainda, é preciso considerar que os híbridos atualmente cultivados são mais exigentes, em termos nutricionais, que as antigas variedades que foram utilizadas nos estudos iniciais. Estes cultivares recentes extraem e exportam grande quantidade de nutrientes.

Rosolem; Malavolta (1981) verificaram que, dentre os nutrientes, o $\mathrm{K}$ é aquele que o sorgo sacarino acumula em maior quantidade e, aproximadamente, $82 \%$ do que é extraído pela cultura é exportado da área de cultivo. Soares et al. (2014) notaram, para as cultivares estudadas, que, quando considerado o colmo, o K é o mais exportado. Com relação à adubação potássica, Coutinho (1983) observou que o fornecimento de $\mathrm{K}$ aumentou significativamente a produção de colmos e a produção máxima foi obtida com a aplicação de $136 \mathrm{~kg} \mathrm{ha}^{-1}$ de $\mathrm{K}_{2} \mathrm{O}$. Outros autores verificaram os efeitos benéficos da adubação potássica na produção de colmos e outros atributos morfofisiológicos do sorgo sacarino (MALAVOLTA et al., 1979; ROSOLEM; MALAVOLTA, 1981).

Assim, objetivou-se com este trabalho avaliar os efeitos da aplicação de doses de $\mathrm{K}$ em atributos morfológicos, produtivos e qualitativos do sorgo sacarino cultivado para a produção de etanol.

\section{MATERIAL E MÉTODOS}

O experimento foi conduzido em condições de campo em área experimental localizada no Instituto Federal de Educação, Ciência e Tecnologia do Triângulo Mineiro (IFTM - Campus Uberaba), no município de Uberaba, MG. O solo da área experimental é classificado, segundos critérios da Embrapa (2013), como Latossolo Vermelho distrófico textura média Antes da instalação do experimento, foi realizada, na camada de $0-0,20 \mathrm{~m}$ de profundidade, amostragem de solo na área experimental, que posteriormente foi submetida a análises químicas, conforme Raij et al. (2001), para caracterização da fertilidade do solo. Os atributos químicos verificados são: $\mathrm{pH}$ $\left(\mathrm{CaCl}_{2}\right) 4,1, \mathrm{MO}=16,5 \mathrm{~g} \mathrm{dm}^{-3}, \mathrm{P}($ resina $)=39 \mathrm{mg} \mathrm{dm}^{-3}, \mathrm{~K}=$ $0,64 \mathrm{mmol}_{\mathrm{c}} \mathrm{dm}^{-3}, \mathrm{Ca}=2,4 \mathrm{mmol}_{\mathrm{c}} \mathrm{dm}^{-3}, \mathrm{Mg}=1,0 \mathrm{mmol}_{\mathrm{c}} \mathrm{dm}^{-3}$, $\mathrm{Al}^{+3}=4,6 \mathrm{mmol}_{\mathrm{c}} \mathrm{dm}^{-3}, \mathrm{H}+\mathrm{Al}=40 \mathrm{mmol}_{\mathrm{c}} \mathrm{dm}^{-3}, \mathrm{CTC}=44,0$ $\mathrm{mmol}_{\mathrm{c}} \mathrm{dm}^{-3}, \mathrm{~V}=9,2 \%, \mathrm{~B}=0,10 \mathrm{mg} \mathrm{dm}^{-3}, \mathrm{Cu}=0,5 \mathrm{mg} \mathrm{dm}^{-3}$, $\mathrm{Fe}=22,3 \mathrm{mg} \mathrm{dm}^{-3}, \mathrm{Mn}=0,5 \mathrm{mg} \mathrm{dm}^{-3} \mathrm{e} \mathrm{Zn}=1,6 \mathrm{mg} \mathrm{dm}^{-3}$.

$\mathrm{O}$ delineamento experimental adotado foi em blocos ao acaso com cinco tratamentos e quatro repetições. Os tratamentos constaram de doses de $\mathrm{K}$, as quais eram: 0, 50, 100,150 e $200 \mathrm{~kg} \mathrm{ha}^{-1}$ de $\mathrm{K}_{2} \mathrm{O}$. Como fonte do nutriente foi utilizado o cloreto de $\mathrm{K}\left(60 \%\right.$ de $\left.\mathrm{K}_{2} \mathrm{O}\right)$ e a aplicação das doses foi realizada a lanço em área total na pré-semeadura (sete dias antes). Após a aplicação, o fertilizante foi incorporado superficialmente por meio de uma gradagem niveladora.

Cerca de noventa dias antes da instalação do experimento, com base nos resultados da análise de solo e nos experimentos realizados por Coutinho et al. (1985, 1987 e 1988), realizou-se a calagem aplicando-se 2,8 tha-1 de calcário $(\mathrm{PRNT}=80,4 \%)$, procurando-se elevar a saturação por bases a $60 \%$. O corretivo foi aplicado na superfície do solo e incorporado até, aproximadamente, $0,20 \mathrm{~m}$ de profundidade por meio de uma aração e duas gradagens.

Todas as parcelas receberam adubação básica de semeadura (25 kg ha-1 de $\mathrm{N}$ e $90 \mathrm{~kg} \mathrm{ha}^{-1}$ de $\left.\mathrm{P}_{2} \mathrm{O}_{5}\right)$ e cobertura nitrogenada (105 $\mathrm{kg} \mathrm{ha}^{-1}$ de $\left.\mathrm{N}\right)$. Utilizou-se na primeira adubação uma mistura de ureia $(45 \%$ de $\mathrm{N})$ e superfosfato simples $\left(18 \%\right.$ de $\left.\mathrm{P}_{2} \mathrm{O}_{5}\right)$ como fonte de $\mathrm{N}$ e $\mathrm{P}$, respectivamente e, na adubação de cobertura, a ureia. A adubação de cobertura foi realizada quando as plantas apresentavam 5 - 6 folhas completamente desenroladas. As doses foram determinadas com base em resultados de Coutinho et al. $(1985,1987$ e 1988).

As parcelas foram constituídas de seis linhas de sorgo sacarino espaçadas em $0,90 \mathrm{~m}$ e com cinco metros de comprimento e foram separadas por carreadores de um metro. A área útil da parcela constou das quatro linhas centrais, desconsiderando-se $0,50 \mathrm{~m}$ no início e no fim da parcela. Os blocos foram separados por carreadores de dois metros. A semeadura foi realizada no mês de dezembro, utilizando-se o híbrido simples SweetMon 2 procurando-se obter população final de 120.000 plantas por hectare. Os demais tratos culturais e fitossanitários adotados foram aqueles recomendados à cultura do sorgo.

Por ocasião do florescimento, com o auxílio de régua graduada, foi medida a distância entre o colo e a inserção da última folha em 10 plantas por parcela e, utilizando-se paquímetro foi medido o diâmetro no primeiro entrenó acima da superfície do solo (expresso em milímetros) de cinco plantas de cada parcela, obtendo-se a altura de plantas e diâmetro de colmos respectivamente. Ainda neste estádio fenológico, para avaliação da concentração de $\mathrm{K}$, foram coletadas em 20 plantas por parcela o terço médio central (sem a nervura) da folha +4 , ou seja, quarta folha com bainha visível a partir do ápice da planta, conforme Coutinho et al. (1985).

No estádio 8 (grão "duro"), de acordo com escala fenológica proposta por Vanderlip; Reeves (1972), foram colhidas as plantas de duas linhas contíguas da área útil de cada parcela, determinando-se a massa fresca de colmos desfolhados e sem a panícula, obtendo-se, então, a produção de colmos

Por ocasião da colheita foram coletados dez colmos por parcela, os quais tiveram o caldo extraído por meio de moenda simples. Posteriormente, a quantidade extraída de caldo foi pesada e, com base na densidade do caldo, os resultados foram expressos em $\mathrm{L} \mathrm{ha}{ }^{-1}$, dessa forma obteve-se a produção de caldo.

A quantificação de açúcares (sacarose, glicose e frutose) foi realizada, com amostras previamente filtradas, em HPLC Shimadzu modelo LC-20A Prominence, com coluna SUPELCOGEL Ca, água deionizada como fase móvel, fluxo de $0,5 \mathrm{~mL} \mathrm{~min}^{-1}$, temperatura do forno de $80^{\circ} \mathrm{C}$ e volume de injeção de $20 \mu \mathrm{L}$, obtendo-se o teor de açúcares totais no caldo. Foi determinado, também, a concentração de $\mathrm{K}$ no caldo segundo metodologia descrita por Bataglia et al. (1983). Ressalta-se, que todas as avaliações para caracterização do caldo foram conduzidas em triplicata.

Para verificar a normalidade dos dados empregou-se o teste de Shapiro-Wilk. Após constatação de normalidade em todas as variáveis, os dados obtidos foram submetidos à análise de variância por meio da aplicação do teste $\mathrm{F}(\alpha=0,05)$ e, quando constatadas diferenças significativas, à análise de regressão polinomial.

\section{RESULTADOS}

Verifica-se na Figura 1 que a adubação potássica proporcionou incrementos lineares no diâmetro dos colmos das plantas de sorgo sacarino $(F=14,78 ; p<0,01)$. Ainda na Figura 1, pela equação do modelo matemático ajustados aos dados, é possível notar que houve aumento de $0,0138 \mathrm{~mm}$ no diâmetro do colmo das plantas de sorgo para cada $1,0 \mathrm{~kg} \mathrm{ha}^{-1}$ 
de $\mathrm{K}_{2} \mathrm{O}$ aplicado. Com a aplicação da maior dose de $\mathrm{K}(200 \mathrm{~kg}$ ha $^{-1} \mathrm{de}_{2} \mathrm{O}$ ) as plantas apresentavam colmos com $18,1 \mathrm{~mm}$ de diâmetro.

Conforme mostrado na Figura 2, com relação à altura de plantas, observa-se que a adubação potássica influenciou significativamente esta variável $(\mathrm{F}=6,29 ; \mathrm{p}<0,01)$ e que a aplicação estimada de $152,2 \mathrm{~kg} \mathrm{ha}^{-1}$ de $\mathrm{K}_{2} \mathrm{O}$ proporcionou a maior altura de plantas $(2,73 \mathrm{~m})$. Os teores de $\mathrm{K}$ na folha diagnóstica não foram influenciados pelas doses do nutriente $(\mathrm{F}=0,99 ; \mathrm{p}>0,05)$. Verifica-se na Figura 3 que o teor médio de $\mathrm{K}$ nas folhas foi de $13 \mathrm{~g} \mathrm{~kg}^{-1}$.

Nota-se, na Figura 4, que a adubação potássica influenciou significativamente a produção de colmos da cultura $(\mathrm{F}=8,84$; $\mathrm{p}<0,01)$ e que o aumento no fornecimento do nutriente proporcionou incremento na produção de colmos até a dose estimada de $132 \mathrm{~kg} \mathrm{ha}^{-1}$ de $\mathrm{K}_{2} \mathrm{O}$. Com aplicação desta dose a produção obtida foi de $32.454 \mathrm{~kg} \mathrm{ha}^{-1}$ de colmos.

$\mathrm{Na}$ Figura 5 observa-se que o aumento das doses de $\mathrm{K}$ também propiciou incrementos significativos e lineares $(\mathrm{F}=$ 9,90; $\mathrm{p}<0,01)$ na produção de caldo. Para cada $1,0 \mathrm{~kg} \mathrm{ha}^{-1} \mathrm{de}$ $\mathrm{K}_{2} \mathrm{O}$ aplicado houve aumento de $11,18 \mathrm{~L} \mathrm{ha}^{-1}$ de caldo, chegando-se a 7.322 $\mathrm{L} \mathrm{ha}^{-1}$ de caldo com a aplicação de 200 $\mathrm{kg} \mathrm{ha}^{-1}$ de $\mathrm{K}_{2} \mathrm{O}$.

Nas Figuras 6 e 7 é possível observar que a adubação potássica influenciou significativamente os teores de açúcar total $(\mathrm{F}=189,12 ; \mathrm{p}<0,01)$ e $\mathrm{K}$ no caldo $(\mathrm{F}=91,61 ; \mathrm{p}<0,05)$ extraído de colmos de sorgo sacarino. Verifica-se nestas figuras que a adição de $\mathrm{K}$ elevou até certo ponto os valores destas variáveis, contudo, a aplicação de doses superiores a 100,8 e 99,0 $\mathrm{kg} \mathrm{ha}^{-1}$ de $\mathrm{K}_{2} \mathrm{O}$ reduziu, respectivamente, a concentração de açúcar total (Figura 6) e de K (Figura 7) no caldo. As maiores concentrações obtidas foram 62,7 e 1143,8 $\mathrm{mg} \mathrm{L}^{-1}$ de açúcar total e $\mathrm{K}$, respectivamente.

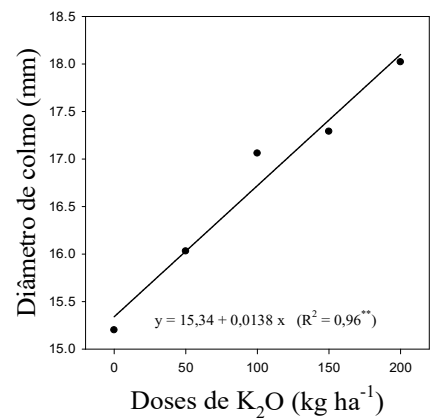

Figura 1. Diâmetro de colmos de plantas de sorgo sacarino em função de doses de potássio

Figure 1. Effects of potassium rates on diameter of sweet sorghum.

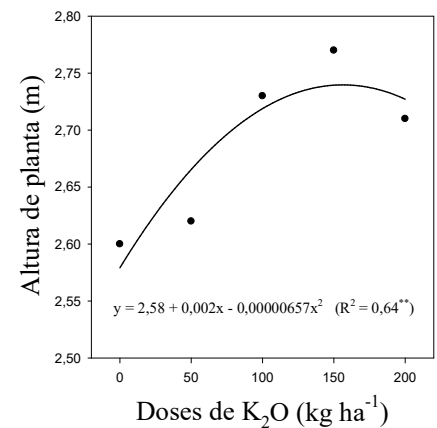

Figura 2. Altura de plantas de sorgo sacarino em função de doses de potássio.

Figure 2. Effects of potassium rates on height of sweet sorghum.

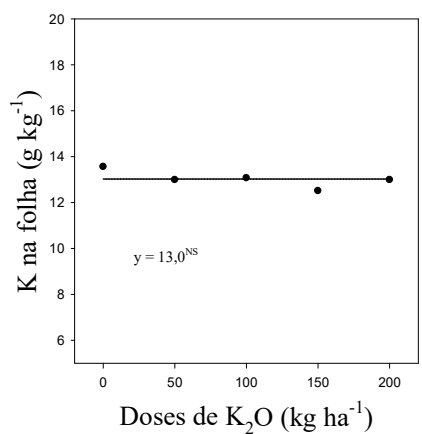

Figura 3. Teor de potássio em folhas de sorgo sacarino em função de doses de potássio.

Figure 3. Effects of potassium rates on leaves $\mathrm{K}$ concentration of sweet sorghum.

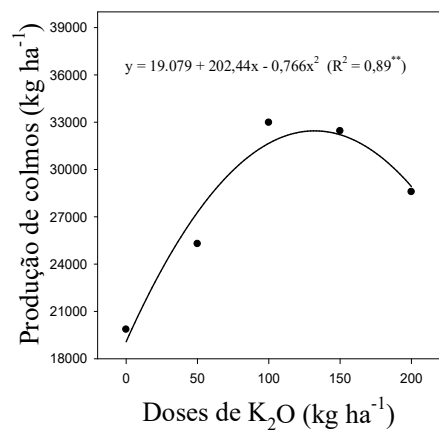

Figura 4. Produção de colmos de sorgo sacarino em função de doses de potássio.

Figure 4. Effects of potassium rates on stem yield of sweet sorghum.

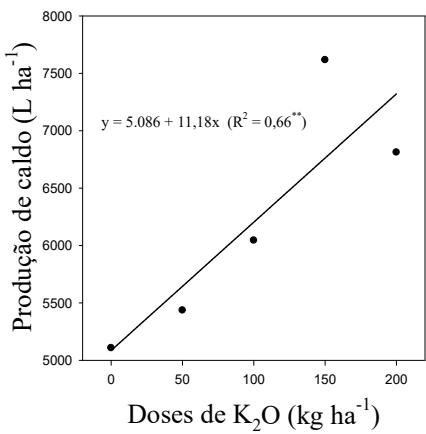

Figura 5. Produção de caldo de sorgo sacarino em função de doses de potássio.

Figure 5. Effects of potassium rates on juice yield of sweet sorghum.

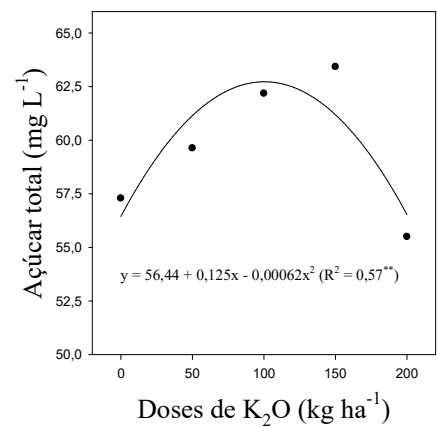

Figura 6. Teor de açúcares totais no caldo de sorgo sacarino em função de doses de potássio.

Figure 6. Effects of potassium rates on total sugar concentration in juice of sweet sorghum. 


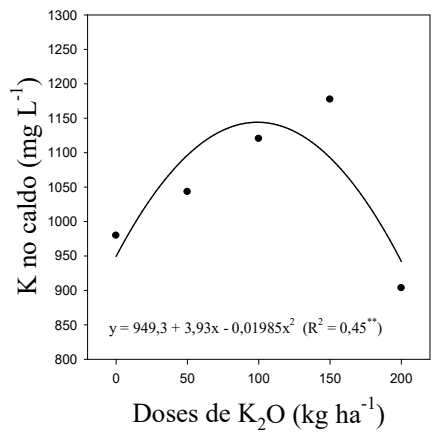

Figura 7. Teor de potássio no caldo de sorgo sacarino em função de doses de potássio.

Figure 7.Effects of potassium rates on $\mathrm{K}$ concentration in juice of sweet sorghum.

\section{DISCUSSÃO}

Quanto ao diâmetro de colmo, Uchôa et al. (2009), trabalhando com a cultura da cana-de-açúcar, também observaram que esta variável foi incrementada em função da adubação potássica. Fernandes et al. (2014b), utilizando a mesma população de plantas adotada neste experimento (120.000 plantas por hectare), verificaram que os colmos de sorgo sacarino possuíam, aproximadamente, $17,00 \mathrm{~mm}$, valor obtido neste trabalho a partir da aplicação de, aproximadamente, $100 \mathrm{~kg} \mathrm{ha}^{-1}$. Lara (2016) chegou a valores, entre, 14,5 a 17,4 mm de diâmetro de colmo, adotando uma dose de $60 \mathrm{~kg} \mathrm{ha}^{-1}$ de $\mathrm{K}_{2} \mathrm{O}$.

No tocante à altura de plantas, segundo Monteiro, et al. (2012), plantas de sorgo sacarino podem atingir mais de 3,5 m de altura. Avaliando 25 cultivares de sorgo sacarino para produção de etanol em cinco municípios de Minas Gerais, Parrella et al. (2010) verificaram que as plantas de sorgo sacarino apresentaram de 2,57 a 3,09 $\mathrm{m}$. Neste trabalho a altura máxima das plantas foi de $2,73 \mathrm{~m}$, obtida com a dose (estimada) de $152,2 \mathrm{~kg} \mathrm{ha}^{-1}$ de $\mathrm{K}_{2} \mathrm{O}$.

Pelo fato de ser uma planta de porte alto e, ainda, produzir quantidade significativa de grãos na panícula, plantas de sorgo sacarino são bastantes sujeitas ao acamamento (WORLEY et al., 1991). Assim, é muito importante estabelecer um manejo da adubação que proporcione diâmetro de colmo e altura de plantas tais que reduzam a probabilidade de acamamento. Neste estudo praticamente não houve acamamento de plantas e isto pode estar associado a uma boa relação entre a altura e o diâmetro de colmos obtidos, mas também pode estar relacionado à alta incidência e severidade de Ergot (Sphacelia sorghi, fase sexuada $=$ Claviceps africana) doença que reduz significativamente a massa da panícula, uma vez que o fungo infecta o ovário não fertilizado, ocupando o lugar do pólen e impedindo a produção de grãos (SILVA et al., 2014), o que acabar por reduzir a probabilidade das plantas acamarem.

Assim como neste trabalho, Rosolem et al. (1985) não verificaram influência significativa do fornecimento de $\mathrm{K}$ no teor do elemento nas folhas de sorgo sacarino, muito embora a aplicação do nutriente tenha incrementado a produção de grãos da cultura. Os autores supracitados verificaram que boas produtividades de colmo e grãos de sorgo sacarino estavam associadas a teores de $\mathrm{K}$ nas folhas (coletadas na parte mediana das plantas por ocasião do emborrachamento) superiores a 15 $\mathrm{g} \mathrm{kg}^{-1}$, valor superior ao verificado neste experimento. Do mesmo modo, Coutinho et al. (1985), considerando a mesma parte da folha e época de amostragem adotadas nestes experimentos, obtiveram teores de $\mathrm{K}$ significativamente superiores, os quais variaram de 24,1 a $26,8 \mathrm{~g} \mathrm{~kg}^{-1}$. É importante mencionar que os autores mencionados trabalharam em solos com teores elevados de $\mathrm{K}$ no solo. Todavia, as variações constatadas entre os experimentos sugerem que novos estudos sejam realizados para subsidiar a avaliação do estado nutricional da cultura por meio da diagnose foliar.

Quanto à produtividade de colmos, Vidal; Neptune (1983) obtiveram valores similares aos deste estudo, os quais, trabalhando em solo com teor inicial de $\mathrm{K}$ de $2,1 \mathrm{mmol}_{\mathrm{c}} \mathrm{dm}^{-3}$, verificaram que a aplicação de $200 \mathrm{~kg} \mathrm{ha}^{-1}$ de $\mathrm{K}_{2} \mathrm{O}$ incorporado ao solo proporcionou a máxima produção de colmos (30.095 $\mathrm{kg} \mathrm{ha}^{-1}$ ). No entanto, Rosolem; Malavolta (1981), trabalhando em um Latossolo Roxo, com teor inicial de $\mathrm{K}$ de 2,7 $\mathrm{mmol}_{\mathrm{c}}$ $\mathrm{dm}^{-3}$ de $\mathrm{K}$ da região de Botucatu - SP, verificaram menor resposta do sorgo sacarino à aplicação de K com o cultivar Rio, uma vez que a máxima produção de colmos $\left(23.070 \mathrm{~kg} \mathrm{ha}^{-1}\right)$ foi obtida com o fornecimento de $146 \mathrm{~kg} \mathrm{ha}^{-1}$ de $\mathrm{K}_{2} \mathrm{O}$. Do mesmo modo, Coutinho (1983) obteve a máxima produtividade de colmos de sorgo sacarino com a aplicação de $136 \mathrm{~kg} \mathrm{ha}^{-1} \mathrm{de} \mathrm{K}_{2} \mathrm{O}$, valor muito próximo ao encontrado neste trabalho.

De fato, o sorgo sacarino apresenta altas exigências nutricionais quanto ao K (ROSOLEM; MALAVOLTA, 1981) e as diferenças observadas entre os resultados do presente estudo e dos demais realizados com a cultura do sorgo sacarino, provavelmente, devem-se aos diferentes teores iniciais de $\mathrm{K}$ no solo e das diferentes exigências nutricionais dos cultivares utilizados no estudo.

Embora a máxima produtividade de colmos obtida neste trabalho se assemelhe àquelas obtidas pelos autores supracitados (década de 80), os cultivares de sorgo sacarino mais recentes têm maior potencial de produção. Atualmente, em áreas de reforma de canaviais, tem-se obtido produtividades próximas a $40.000 \mathrm{~kg} \mathrm{ha}^{-1}$ de massa de colmo (MAY et al., 2014) e nas melhores condições de cultivo temse observado a produções superiores a $70.000 \mathrm{~kg} \mathrm{ha}^{-1}$ de colmos (FERNANDES et al., 2014b). A menor produção obtida no presente experimento com relação àqueles realizados com cultivares recentes de sorgo sacarino, provavelmente, deve-se a alta incidência e severidade de Ergot e Antracnose foliar (Colletotrichum sublineolum) [dados não apresentados] e também ao período de ausência de chuvas (17 dias) durante o mês de fevereiro.

Referente à produção de caldo, Albuquerque et al. (2012), cultivando sorgo sacarino (BRS 506) em solo com teor inicial de $1,6 \mathrm{mmol}_{\mathrm{c}} \mathrm{dm}^{-3}$ de $\mathrm{K}$ em três regiões de Minas Gerais, obtiveram, em média, $7.190 \mathrm{~kg} \mathrm{ha}^{-1}$ de caldo, valor semelhante ao obtido no presente trabalho.

Observa-se, ainda, que a adição de $\mathrm{K}$ elevou os valores de teores de açúcar total e concentração de $\mathrm{K}$ no caldo. No entanto, este incremento foi observado apenas até a aplicação de, aproximadamente, $100 \mathrm{~kg} \mathrm{ha}^{-1}$ de $\mathrm{K}_{2} \mathrm{O}$. Doses superiores acabaram por reduzir drasticamente tanto os teores de açúcar total quanto a concentração de K no caldo. Pérez; Melgar (2000), estudando a cultura da cana-de-açúcar, também constataram que a aplicação de doses crescentes de K, além de aumentar a produtividade de colmos, promoveu aumentos significativos na quantidade de açúcar do caldo. Os teores de açúcar total observados neste trabalho, independentemente da dose de K aplicada, são semelhantes aos obtidos por Malavolta et al. (1979) em plantas bem nutridas (cv. Brandes) de sorgo sacarino $\left(61,5 \mathrm{~g} \mathrm{~L}^{-1}\right)$. No entanto, estão muito aquém daqueles 
observados por Fernandes et al. (2014a), que ao avaliarem a marcha de acúmulo de açúcares em quatro cultivares de sorgo sacarino (BRS 506, BRS 508, BRS 509 e BRS 511), notaram teores de até $190 \mathrm{~g} \mathrm{~L}^{-1}$.

Os efeitos benéficos do fornecimento de $\mathrm{K}$ nos atributos morfológicos, produtivos e qualitativos das plantas de sorgo sacarino observados neste experimento, estão relacionados à importância deste elemento no processo fotossintético, ou seja, na transformação da energia luminosa em energia química (ATP e NADPH). Como todas as funções vitais da planta dependem, direta ou indiretamente, de ATP e NADPH, a adequada disponibilidade de $\mathrm{K}$ às plantas poderá proporcionar maior eficiência enzimática, melhor controle de abertura e fechamento estomático, maior assimilação de $\mathrm{CO}_{2}$, maior translocação de carboidratos e maior síntese de açúcares (FORNASIERI FILHO; FORNASIERI, 2009).

\section{CONCLUSÕES}

A adubação potássica influenciou positivamente os atributos morfológicos, produtivos e qualitativos do sorgo sacarino. A dose estimada que proporcionou a maior produtividade de colmos (32.454 $\left.\mathrm{kg} \mathrm{ha}^{-1}\right)$ foi de $132 \mathrm{~kg} \mathrm{ha}^{-1} \mathrm{de}$ $\mathrm{K}_{2} \mathrm{O}$. As maiores concentrações de açúcar total $\left(62,7 \mathrm{mg} \mathrm{L}^{-1}\right)$ e $\mathrm{K}$ no caldo (1.144 $\mathrm{mg} \mathrm{L}^{-1}$ ) foram obtidas com a aplicação de, aproximadamente, $100 \mathrm{~kg} \mathrm{ha}^{-1}$ de $\mathrm{K}_{2} \mathrm{O}$.

\section{AGRADECIMENTOS}

Os autores expressam agradecimento à Fapemig pela concessão de bolsa de iniciação científica ao último autor.

\section{REFERÊNCIAS}

ALBUQUERQUE, C. J. B.; TARDIN, F. D.; PARRELLA, R. A. C.; GUIMARÃES, A. S.; OLIVEIRA, R. M.; SILVA, K. M. J. Sorgo sacarino em diferentes arranjos de plantas e localidades de Minas Gerais, Brasil. Revista Brasileira de Milho e Sorgo, Sete Lagoas, v. 11, n.1, p. 69-85, 2012. DOI: 6477/rbms.v11n1p69-85

ALMODARES, A.; HADI, M. R. Production of bioethanol from sweet sorghum: A review. African Journal of Agricultural Research, v. 4, n. 9, p. 772-780, 2009.

BATAGLiA, O. C.; FURLANI, A. M. C.; TEIXEIRA, J. P. F.; FURLANI, P. R.; GALLO, J. R. Métodos de análise química de plantas. Campinas: Instituto Agronômico, 1983. 48 p. (Boletim Técnico, 78).

COUTINHO, E. L. M. Efeitos da adubação nitrogenada, fosfatada e potássica na cultura do sorgo sacarino analisada pela diagnose foliar, produção de colmos e álcool etílico. 1983. 69f. Tese (Doutorado em Agronomia) - Escola Superior de Agricultura "Luiz de Queiroz", Piracicaba, 1983.

COUTINHO, E. L. M.; FARES, J. C.; PINTO, A. G.; SOUZA, E. C. A. de. Efeitos da adubação nitrogenada e potássica na cultura do sorgo sacarino (Sorghum bicolor L. Moench), avaliados pela diagnose foliar, produção de colmos e etanol. Científica, São Paulo, v. 16, n. 2, p. 261$270,1988$.

COUTINHO, E. L. M.; NEPTUNE, A. M. L.; SOUZA, E. C. A.; SORIANO, A. G. Calagem e diagnose foliar em sorgo sacarino (Sorghum bicolor L. Moench). Anais da Escola Superior de Agricultura "Luiz de Queiroz", Piracicaba, v. 42 , n. 1, p. 33-49, 1985. DOI: http://dx.doi.org/10.1590/S0071-12761985000100004
COUTINHO, E. L. M.; TEDRUS, P. F. A.; BANZATTO, D. A.; SOUZA, E. C. A. Efeitos da adubação nitrogenada e fosfatada na cultura do sorgo sacarino (Sorghum bicolor L. Moench), avaliados pela diagnose foliar, produção de colmos e etanol. Científica, São Paulo, v. 15, n. 1/ n. 2, p. 137-146, 1987.

DURÃES, F. O. M. Sorgo sacarino: tecnologia agronômica e industrial para alimentos e energia. Agroenergia em Revista, Brasília, v. 2, n. 3, p. 14-52, 2011.

EMBRAPA EMPRESA BRASILEIRA DE PESQUISA AGROPECUÁRIA. Sistema brasileiro de classificação de solos. 3. ed. Brasília: Embrapa, 2013. 353 p.

FERNANDES, G.; BRAGA, T. G.; FISCHER, J.; PARRELLA, R. A. C.; RESENDE, M. M. de R.; CARDOSO, V. L. Evaluation of potential ethanol production and nutrients for four varieties of sweet sorghum during maturation. Renewable Energy, Oxford, v. 71, p. 518-524, 2014a. DOI: https://doi.org/10.1016/j.renene.2014.05.033

FERNANDES, P. G.; MAY, A.; COELHO, F. C.; ABREU, M. C.; BERTOLINO, K. M. Influência do espaçamento e da população de plantas de sorgo sacarino em diferentes épocas de semeadura. Ciência Rural, Santa Maria, v. 44, n. $6, \quad$ p. $975-981$, 2014b. DOI: http://dx.doi.org/10.1590/S0103-84782014000600004

FORNASIERI FILHO, D.; FORNASIERI, J. L. Manual da cultura do sorgo. Jaboticabal: FUNEP, 2009. 202 p.

LARA, J. P. Desempenho agroindustrial e forrageiro do sorgo sacarino em função da adubação nitrogenada e potássica. 2016. 66f. Dissertação (Mestrado em Ciência Agrárias) - Universidade Federal de São João del-Rei, 2016

LOURENÇO, M. E. V.; MASSA, V. M. L.; PALMA, P. M. M.; RATO, A. E. M. Potencialidades do sorgo sacarino [Sorghum bicolor (L.) Moench] para a produção sustentável de bioetanol no Alentejo. Revista de Ciências Agrárias, Lisboa, v. 30, n. 1, p. 103-110, 2007.

MALAVOLTA, E.; COUTINHO, E. L. M.; VITTI, G. C.; ALEJO, N. U.; NOVAES, N. J.; FURLANI NETRO, V. L. Estudos sobre a nutrição mineral do sorgo sacarino (Sorghum bicolor (L) Moench). I. Deficiências de macro e micronutrientes e toxidez de alumínio, cloro e manganês. Anais da Escola Superior de Agricultura "Luiz de Queiroz", Piracicaba, v. 36, p. 173-202, 1979. DOI: https://dx.doi.org/10.1590/S0071-12761979000100011

MAPA_MINISTÉRIO DA AGRICULTURA PECUÁRIA E ABASTECIMENTO. Produção brasileira de cana-deaçúcar, açúcar e etanol. Disponível em: $<$ http://www.agricultura.gov.br/assuntos/sustentabilidade/ agroenergia/arquivosproducao/copy13_of_07_prodsucroa lcooleiraBR.pdf $>$. Acesso em: 1 out 2017.

MAY, A.; MENDES, S. M.; SILVA, D. D. da; PARRELLA, R. A. da C.; MIRANDA, R. A. de; SILVA, A. F. da; PACHECO, T. F.; AQUINO, L. A. de; COTA, L. V.; COSTA, R. V. da; KARAM, D.; PARRELLA, N. N. L. D.; SCHAFFERT, R. E. Cultivo de sorgo sacarino em áreas de reforma de canaviais. Sete Lagoas: Embrapa Milho e Sorgo, 2013. 36 p. (Circular Técnica, 186).

MAY, A.; PARRELLA, R. A. da C.; DAMASCENO, C. M. B.; SIMEONE, M. L. F. Sorgo como matéria-prima para produção de bioenergia: etanol e cogeração. Informe Agropecuário, Belo Horizonte, v. 35, n. 278, p. 14-20, 2014. 
MONTEIRO, J. S. T.; HAVRLAND, B.; INANOVA, T. Sweet sorghum (Sorghum bicolor (L.) Moench) bioenergy value - importance for Portugal. Agricultura Tropica et Subtropica, Suchdol, v. 45, n. 1, p. 12-19, 2012. DOI: https://dx.doi.org/10.2478/v10295-012-0002-y

PARRELlA, R. A. C.; MENEGUCI, J. L. P.; RIBEIRO, A.; SILVA, A. R.; PARRELA, N. N. L. D.; RODRIGUES, J. A. dos S.; TARDIN, F. D.; SCHAFFERT, R. E. Desempenho de cultivares de sorgo sacarino em diversos ambientes visando produção de etanol. In: CONGRESSO NACIONAL DE MILHO E SORGO, 28., 2010, Goiânia, GO. Anais... Goiânia: ABMS, 2010. p. 2858-2866.

PÉREZ, O; MELGAR, M. Sugar cane response to nitrogen, phosphorus and potassium application in Andisol soils. Better Crops International, Atlanta, v. 12, n. 2, p. 20-23, 1998.

RAIJ, B. V.; ANDRADE, J. C.; CANTARELA, H.; QUAGGIO, J. A. Análise química para avaliação da fertilidade de solos tropicais. Campinas: Instituto Agronômico, 2001. 284 p.

RAUPP, A. A. A.; CORDEIRO, D. S.; PETRINI, J. A; PORTO, M. P.; BRANCÃO, N.; SANTOS FILHO, B. G. A cultura do sorgo sacarino na região sudeste do Rio Grande do Sul. Pelotas: Embrapa, 1980. (Circular Técnica, 12)

ROSOLEM, C. A.; MACHADO, J. R.; BRINHOLI, O. Efeito de adubação nitrogenada, fosfatada, e potássica no sorgo sacarino e um latossolo roxo. Pesquisa Agropecuária Brasileira, Brasília, v. 20, n. 6, p.635-641, 1985.

ROSOLEM, C. A.; MAVOLTA, E. Exigências nutricionais do sorgo sacarino. Anais da Escola Superior de Agricultura Luiz de Queiroz, Piracicaba, v. 38, n. 1, p. 257-268, 1981. DOI: https://dx.doi.org/10.1590/S0071-
SILVA, D. D. da; COTA, L. V.; COSTA, R. V. da; PARREIRA, D. F. Principais doenças do sorgo. Informe Agropecuário, Belo Horizonte, v. 35, n. 278, p. 102-111, 2014.

SOARES, E.R.; COUTINHO, E.L.M.; RAMOS， S.B.; SILVA, M.S. da; BARBOSA, J.C. Acúmulo de matéria seca e macronutrientes por cultivares de sorgo sacarino. Semina: Ciências Agrárias, Londrina, v. 35, n. 6, p. 3015-3030, 2014.

UCHÔA, S. C. P.; ALVES JÚNIOR, H. de O.; ALVES, J. M. A.; MELO, V. F.; FERREIRA, G. B. Resposta de seis variedades de cana-de-açúcar a doses de potássio em ecossistema de cerrado de Roraima. Revista Ciência Agronômica, Fortaleza, v. 40, n. 4, p. 505-513, 2009.

VANDERLIP, R. L.; REEVES, H. E. Growth stages of sorghum (Sorghum bicolor (L.) Moench). Agronomy Journal, Madison, v. 64, p. 13-16, 1972. DOI: https://dx.doi.org/10.2134/agronj1972.000219620064000 $10005 x$

VIDAL, A. A.; NEPTUNE, A. M. L. Aproveitamento de algumas fontes de potássio pelo sorgo sacarino (Sorghum bicolor (L.) Moench). Anais da Escola Superior de Agricultura "Luiz de Queiroz", Piracicaba, v. 40, p. 1333-1370, 1983. DOI: https://dx.doi.org/10.1590/S007112761983000200027

WORLEY, J. W.; CUNDIFF, J. S.; VAUGHAN, D. H.; PARRISH, D. J. Influence of sweet sorghum spacing on stalk pith yield. Bioresource Technology, Essex, v. 36, n. 2, p. 133-139, $1991 . \quad$ DOI: https://dx.doi.org/10.1016/0960-8524(91)90170-O 